\title{
EDITORIAL
}

\section{The role of inhaled corticosteroids in the management of acute asthma}

\author{
B.H. Rowe* and D. Vethanayagam ${ }^{\#}$
}

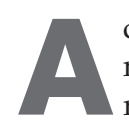

cute exacerbations are common occurrences for asthmatics. Contact with airway irritants (e.g. viral upper respiratory tract infections, aero-allergens) and nonadherence to controller medications, along with the natural history of the disease can result in deterioration in lung function, increased symptoms and an increased need for reliever medication. It is estimated that nearly 2 million emergency department (ED) asthma visits occur annually in the USA alone [1]. Since the frequency of exacerbations is related to asthma severity on the one hand, and increasing degrees of airway eosinophilia are associated with increased disease severity on the other [2], understanding the pathophysiology of exacerbations is critically important to disease control.

The medical consequences of these events can range from minor life interruptions to severe illness. These severe exacerbations often result in ED presentation or unscheduled visits to health professionals for urgent care, and may require hospital admission. While rare, death from exacerbations does occur. The economic consequences of asthma have been well documented $[3,4]$ and the acute attack has been estimated to represent $\sim 25 \%$ of overall asthma costs [5]. The control of chronic asthma with the use of inhaled corticosteroids (ICS), with or without the use of additional agents (e.g. long-acting $\beta$ agonists or leukotriene receptor antagonists), anticholinergics and in some cases newer biological agents, have proven effective in reducing the frequency and severity of these exacerbations. In addition, nonpharmacological approaches (regular follow-up, action plans, immunisation, asthma education) have also proven to be effective but adherence to these can be low $[6,7]$.

Despite these advances, a gap between what is known and what is practiced hampers efforts to improve the quality of life of patients with asthma. This gap may be the result of poor access to care and resources, failure of physicians to treat the

Depts of *Emergency Medicine and ${ }^{\#}$ Medicine, University of Alberta, and Capital Health, Edmonton, Canada.

SUPPORT STATEMENT: B.H. Rowe is supported by the 21st Century Research Chair Program from the Government of Canada (Ottawa, Canada).

STATEMENT OF INTEREST: Statements of interest for all authors of this manuscript can be found at www.erj.ersjournals.com/misc/statements.shtml

CORRESPONDENCE: B.H. Rowe, Dept of Emergency Medicine, University of Alberta, 1 G1.43 WMC, 8440-112th Street, Edmonton, Alberta, Canada T6G 2B7. Fax: 1 7804073982. E-mail: brian.rowe@ualberta.ca disease aggressively, poor penetration of asthma education to the most needy and/or inability to afford controller medications. Not surprisingly, asthma visits to EDs and other settings remain an important health problem and an area of intense research [8]. Current research suggests that patients with acute asthma should be treated with short-acting inhaled $\beta$-agonists [9], inhaled ipratropium bromide [10] and systemic corticosteroids (oral or intravenous) [11]. Patients who fail to improve following this approach or who are severe at presentation may also receive intravenous magnesium sulfate $\left(\mathrm{MgSO}_{4}\right)$ [12], inhaled and injectable adrenaline and/or noninvasive ventilation [13]. Other treatments (e.g. inhaled $\mathrm{MgSO}_{4}$ [14] or heliox [15]) likely provide small benefit; however, evidence is limited. Other agents (e.g. intravenous $\beta$-agonists [16], aminophylline [17], antibiotics [18]) have not been found to be effective.

An emerging area of study is the role of ICS agents in the treatment of acute asthma. Traditional teaching suggests that the mechanisms for corticosteroids require hours to days to become established. Transport into the cell and nuclear membrane results in changes in protein synthesis which are later translated into clinical improvements as measured by return of symptom control and improved physiological parameters (e.g. spirometry, challenge testing sensitivity) [19]. This theory has been challenged by a number of researchers and the clinical evidence is summarised in a Cochrane review [20]. Currently, there are a number of high-quality studies in which ICS has been compared with standard care [20]. The review examined the effect of ICS alone and in addition to systemic corticosteroids in the early treatment of acute asthma. Trials in which ICS was compared with placebo demonstrate a clear reduction in admissions for this patient group (relative risk (RR) 0.32 ; 95\% confidence interval (CI) $0.18-0.58$ ). For the addition of ICS to systemic corticosteroids, the evidence was homogeneous, yet somewhat underpowered to draw clear conclusions on admission outcomes (RR 0.56; 95\% CI 0.29 1.09). Moreover, it was only when all ICS studies were pooled that clinically and statistically significant effects were observed on admissions (RR 0.39; 95\% CI 0.25-0.61). Finally, the evidence was heterogeneous and conflicting (pooling not possible) in the seven trials where ICS was compared with systemic corticosteroids.

The research reported by BELDA et al. [21], in the current issue of the European Respiratory Journal, provides additional understanding regarding the mechanisms at work during the treatment of an acute exacerbation. In this multiple-blind, double-dummy, randomised controlled trial with concealed 
allocation, 39 adults with acute asthma received either highdose fluticasone $\left(4,000 \mu \mathrm{g} \cdot \mathrm{day}^{-1}\right)$ or prednisone $\left(30 \mathrm{mg} \cdot \mathrm{day}^{-1}\right)$ for 4 days. The patients were followed with induced sputum and blood inflammatory markers at baseline, 2, 6 and $24 \mathrm{~h}$. The study was designed to identify the mechanism underlying the early effects seen with the administration of ICS in acute asthma. The results suggest that the inflammatory markers and clinical condition in both groups improved over the 24-h period; however, sputum eosinophil counts improved faster in the fluticasone group while serum eosinophils counts improved faster in the prednisone group. This reflects, in part, the fact that different compartments demonstrate differential "recovery" periods following an exacerbation, which is partially explained by the route of drug delivery.

This study illustrates several other important facts. First, 15 out of the 39 patients were not using ICS agents prior to their ED presentation. This is despite the fact that patients with acute asthma often exhibit many of the risk factors suggestive of poorly controlled asthma [22]. Secondly, using traditional measures (e.g. symptoms, pulmonary functions and so on) there was no statistical difference between the two groups in their improvement; however, differences emerged when inflammatory markers were examined. The use of induced sputum as a diagnostic tool has been available for nearly 60 yrs. Protocol standardisation [23] for both diagnosis and monitoring of airway disease [24] has increased the understanding of the role of sputum cell counts and other markers of inflammation. Consequently, this has resulted in identification of various phenotypic subtypes of asthma and has been an important advance within the clinical realm. Unfortunately, the availability of this diagnostic test is limited to some major centres where tertiary care of asthmatics is provided. The availability of this technique is, in part, related to a region's ability to perform these inductions with safety measures in place (e.g. infection precautions, spirometry monitoring, physician supervision) along with appropriate lab facilities to process the specimens in a timely manner. It is important to explore alternatives to this method of measurement, especially in children under the age of 6 yrs, where this tool has limited value due to inability of these patients to expectorate sputum and perform spirometry reliably. Although exhaled nitric oxide levels have been used in some centres (for both adult and paediatric patients), it only measures a single parameter, most closely linked to eosinophilic airway inflammation. This does not assess different inflammatory subtypes noted in asthma [25]. Recent research advances, such as exhaled breath condensates, are important advances which warrant further study. As the evaluation of newer tools used to measure inflammation increases, understanding of the application of these measures within clinical practice in both the diagnosis and ongoing management of asthma will evolve [26].

This work complements ongoing efforts to improve clinical outcomes using ICS in conjunction with systemic steroids. What other evidence do we have? Some of the earliest evidence for the role of ICS in acute respiratory conditions arose from the treatment of children with croup in the ED. In a small study, researchers showed that ICS were efficacious in this paediatric airway disease [27]. In outpatient asthma, evidence now suggests that systemic corticosteroids should be used in most patients, with as few as five patients needing treatment to prevent one relapse [28]. The evidence for the addition of ICS to this regimen arises from yet another Cochrane review [29]. In this review, all of the available evidence has been pooled and suggests that there is a strong trend in support of treatment of asthmatics with both treatments following discharge (RR 0.75; 95\% CI 0.52-1.09).

There are, however, many questions that remain unanswered. First, would the ICS effect be similar in those previously using ICS compared with those who were not? In recent clinical studies, the prior use of ICS agents was highly predictive of poorer outcomes as measured by quality of life and relapse rates [30]. Secondly, different types of exacerbations (e.g. viral as opposed to allergen-induced) may produce different degrees of protein leak, a hallmark of asthma [31]. Therefore, the type of exacerbation could significantly impact the degree of protein leak [32]. Thirdly, differential gastrointestinal absorption of prednisone among individuals is a potentially important unreported confounder. Finally, most clinicians would prefer to know the physiological benefit of ICS in addition to systemic corticosteroids in acute asthma, and we eagerly await those research results.

In summary, BELDA et al. [21] provide important pathophysiological evidence of the importance of inhaled corticosteroids in the management of acute asthma. Some clinicians have been using this management strategy based on subjective evidence of improvement in a clinical setting; however, the increasing body of evidence suggests that addressing both compartments (systemic and airway) is a more effective approach than treating either alone. Additional work on dose and duration of inhaled corticosteroid treatment as well as the combination of inhaled corticosteroids and corticosteroids are needed. However, until then, clinicians treating these patients should consider the early addition of inhaled corticosteroids in the emergency department and continuation of these preventive agents following discharge.

\section{ACKNOWLEDGEMENTS}

The authors would like to thank D. Milette (University of Alberta, Edmonton, AB, Canada) for her secretarial support.

\section{REFERENCES}

1 Mannino DM, Homa DM, Pertowski CA, et al. Surveillance for asthma - United States, 1960-1995. MMWR CDC Surveill Summ 1998; 47: 1-28.

2 Louis R, Lau LCK, Bron AO, Roldaan AC, Radermecker M, Djukanovic R. The relationship between airways inflammation and asthma severity. Am J Respir Crit Care Med 2000; 161: 9-16.

3 Weiss KB, Sullivan SD. The health economics of asthma and rhinitis. I. Assessing the economic impact. J Allergy Clin Immun 2001; 107: 3-8.

4 Serra-Batlles J, Plaza V, Morejon E, Comella A, Brugues J. Costs of asthma according to the degree of severity. Eur Respir J 1998; 12: 1322-1326.

5 Krahn MD, Berka C, Langlois P, Detsky AS. Direct and indirect costs of asthma in Canada. CMAJ 1996; 154: 821-831. 
6 Tsuyuki RT, Sin DD, Sharpe HM, et al. Management of asthma among community-based primary care physicians. J Asthma 2005; 42: 163-167.

7 Chapman KR, Ernst P, Grenville A, Dewland P, Zimmerman S. Control of asthma in Canada: failure to achieve guideline targets. Can Respir J 2001; 8, Suppl. A, 35A-40A.

8 Mannino DM, Homa DM, Akinbami LJ, Moorman JE, Gwynn C, Redd SC. Surveillance for Asthma - United States, 1980-1999. MMWR Surveill Summ 2002; 51: 1-13.

9 Cates CJ, Crilly JA, Rowe BH. Holding chambers (spacers) versus nebulisers for $\beta$-agonist treatment of acute asthma. Cochrane Database of Syst Rev 2006; 2: CD000052.

10 Stoodley RG, Aaron SD, Dales RE. The role of ipratropium bromide in the emergency management of acute asthma exacerbation: a meta-analysis of randomized clinical trials. Ann Emerg Med 1999; 34: 8-18.

11 Rowe BH, Spooner C, Ducharme FM, Bretzlaff JA, Bota GW. Early emergency department treatment of acute asthma with systemic corticosteroids. Cochrane Database Syst Rev 2001; 1: CD002178.

12 Rowe BH, Bretzlaff JA, Bourdon C, Bota GW, Camargo CA Jr. Magnesium sulfate for treating exacerbations of acute asthma in the emergency department. Cochrane Database Syst Rev 2000; 1: CD001490.

13 Ram FSF, Wellington SR, Rowe BH, Wedzicha JA. Noninvasive positive pressure ventilation for treatment of respiratory failure due to severe acute exacerbations of asthma. Cochrane Database Syst Rev 2005; 1: CD004360.

14 Blitz M, Blitz S, Beasely R, et al. Inhaled magnesium sulfate in the treatment of acute asthma. Cochrane Database Syst Rev 2005; 4: CD003898.

15 Rodrigo G, Pollack C, Rodrigo C, Rowe BH. Heliox for nonintubated acute asthma patients. Cochrane Database Syst Rev 2006; 4: CD002884.

16 Travers A, Jones A, Camargo CA Jr, Rowe BH. Intravenous $\beta 2$-agonists for acute asthma in the emergency department. Cochrane Database Syst Rev 2001; 1: CD002988.

17 Parameswaran K, Belda J, Rowe BH. Addition of intravenous aminophylline to $\beta 2$-agonists in adults with acute asthma. Cochrane Database Syst Rev 2000; 4: CD002742.

18 Graham VAL, Lasserson T, Rowe BH. Antibiotics for acute asthma. Cochrane Database Syst Rev 2001; 2: CD002741.

19 Chan L, O'Malley BW. Steroid hormone action: recent advances. Ann Intern Med 1978; 89: 694-701.

20 Edmonds ML, Camargo CA Jr, Pollack CV, Rowe BH. Early use of inhaled corticosteroids in the emergency department treatment of acute asthma. Cochrane Database of Syst Rev 2003; 3: CD002308.

21 Belda J, Margarit G, Martinez C, et al. Anti-inflammatory effects of high-dose inhaled fluticasone versus oral prednisone in asthma exacerbations. Eur Respir J 2007; 30: 1143-1149.

22 Rowe BH, Bota GW, Fabris L, Therrien SA, Milner RA, Jacono J. Inhaled budesonide in addition to oral corticosteroids to prevent relapse following discharge from the emergency department: a randomized controlled trial. JAMA 1999; 281: 2119-2126.

23 Pizzichini E, Pizzichini MM, Efthimiadis A, et al. Indices of airway inflammation in induced sputum: reproducibility and validity of cell and fluid-phase measurements. Am J Respir Crit Care Med 1996; 154: 308-317.

24 Jayaram L, Pizzichini MM, Cook RJ, et al. Determining asthma treatment by monitoring sputum cell counts: effect on exacerbations. Eur Respir J 2006; 27: 483-494.

25 Simpson JL, Scott R, Boyle MJ, Gibson PG. Inflammatory subtypes in asthma: assessment and identification using induced sputum. Respirology 2006; 11: 54-61.

26 Green RH, Brightling CE, McKenna S, et al. Asthma exacerbations and sputum eosinophil counts: a randomised controlled trial. Lancet 2002; 360: 1715-1721.

27 Klassen TP, Feldman ME, Watters LK, Sutcliffe T, Rowe PC. Nebulized budesonide for children with mild-to-moderate croup. N Engl J Med 1994; 331: 285-289.

28 Rowe BH, Spooner CH, Ducharme FM, Bretzlaff JA, Bota GW. Corticosteroids for preventing relapses following acute exacerbations of asthma. Cochrane Database Syst Rev 2001; 1: CD000195.

29 Edmonds ML, Camargo CA Jr, Brenner B, Rowe BH. Inhaled steroids in acute asthma following emergency department discharge. Cochrane Database of Syst Rev 2000; 3: CD002316.

30 Rowe $\mathrm{BH}$, Wong $\mathrm{E}$, Blitz $\mathrm{S}$, et al. Adding long-acting $\beta$ agonists to inhaled corticosteroids after discharge from the emergency department for acute asthma: a randomized controlled trial. Acad Emerg Med 2007; (In Press).

31 Persson CC. The role of microvascular permeability in the pathogenesis of asthma. Eur Journal Respir Dis Suppl 1986; 144: S190-S216.

32 Wedde-Beer $\mathrm{K}, \mathrm{Hu} \mathrm{C}$, Rodriguez MM, Piedimonte G. Leukotrienes mediate neurogenic inflammation in lungs of young rats infected with respiratory syncytial virus. Am J Physiol 2002; 282: L1143-L1150. 